\title{
A insustentável leveza do alumínio: impactos socioambientais da inserção do Brasil no mercado mundial de alumínio primário
}

\author{
The unbearable lightness of aluminum: the social \\ and environmental impacts of Brazil's insertion \\ in the primary aluminum global market
}

Alen Batista Henriques ${ }^{1}$

Marcelo Firpo Souza Porto ${ }^{2}$

\footnotetext{
${ }^{1}$ Faculdade de Educação, Universidade do Estado de Minas Gerais - Unidade de Leopoldina. R. General Olimpio Mourão Filho s/n, Pirineus. 36.700-000 Leopoldina MG Brasil. alenhenriques@gmail.com ${ }^{2}$ Escola Nacional de Saúde Pública Sérgio Arouca, Fiocruz.
}

\begin{abstract}
This article assesses aluminum production in Brazil and its social, environmental and public health impacts. The effects of the aluminum production chain challenge the idea of sustainable growth affirmed by business groups that operate in the sector. This article upholds the theory that the insertion of Brazil in the global aluminum market is part of a new configuration of the International Division of Labor (IDL), the polluting economic and highly energy dependent activities of which - as is the case of aluminum have been moving to peripheral nations or emerging countries. The laws in such countries are less stringent, and similarly the environmental movements and the claims of the affected populations in the territories prejudiced in their rights to health, a healthy environment and culture are less influential. The competitiveness of this commodity is guaranteed in the international market, from the production of external factors such as environmental damage, deforestation, emissions of greenhouse gases and scenarios of environmental injustice. This includes undertakings in the construction of hydroelectric dams that expose traditional communities to situations involving the loss of their territories.
\end{abstract}

Key words Primary aluminum industry, Environmental impacts, Environmental justice
Resumo O presente artigo procura discutir a produção de alumínio no Brasil e seus impactos socioambientais e à saúde pública. Os impactos da cadeia produtiva do aluminio colocam em xeque a ideia de crescimento sustentável difundido pelos grupos empresariais que atuam no setor. $O$ artigo defende a tese de que a inserção do Brasil no mercado global do alumínio faz parte de uma nova configuração da Divisão Internacional do Trabatho (DIT), cujas atividades econômicas poluentes $e$ altamente dependentes de energia, como o caso deste metal vêm se deslocando para nações periféricas ou emergentes, onde muitas vezes as legislações são menos austeras, do mesmo modo como são menos influentes os movimentos ambientalistas e as reivindicações das populações atingidas nos territórios afetados em seus direitos à saúde, ao ambiente saudável è cultura. A competitividade desta commodity é garantida no mercado internacional, a partir da produção de externalidades como os danos ao ambiente, desmatamentos, emissões de gases do efeito estufa e de cenários de injustiça ambiental, como também nos empreendimentos de construção de barragens hidrelétricas que expõem comunidades tradicionais a situações que envolvem a perca de seus territórios.

Palavras-chave Indústria de aluminio primário, Impactos ambientais, Justiça Ambiental 


\section{Introdução}

Este artigo discute alguns dos impactos socioambientais e sobre a saúde pública na sociedade brasileira pela produção de alumínio. Embora o tema ambiente e desenvolvimento estejam sendo crescentemente discutidos, no campo da saúde pública brasileira, em especial após a Rio $92^{1} \mathrm{e}$ recentemente na Rio $+20^{2,3}$, a análise desta cadeia produtiva específica e de crescente importância para o país ainda não vem sendo analisada pela academia.

Para esta análise, incorporamos no artigo os referenciais teóricos do metabolismo social, da ecologia política e da justiça ambiental, uma vez que os mesmos auxiliam na compreensão dos problemas sociais, de saúde coletiva e meio ambiente articulados aos processos e modelos de desenvolvimento, adotados por nações semiperiféricas e emergentes como o Brasil.

O uso de recursos não renováveis é um gerador de processos entrópicos mundo afora, principal causador do efeito estufa e de vários problemas de saúde ambiental e dos trabalhadores. As características dessa fonte energética, assim como de commodities agrícolas e metálicas, que ao se articular aos atuais padrões de consumo das nações centrais do capitalismo criam fluxos de materiais e energia que se incompatibilizam com o metabolismo social e ecológico do planeta, adquirindo de tal modo um caráter injusto e insustentável ${ }^{4}$.

O paradigma da economia ecológica permite descortinar os conflitos e as chamadas externalidades ambientais negativas, que são produzidas no interior de países mais periféricos, por atividades econômicas que objetivam atender a demanda e aos interesses do mercado global, controlados pelas nações e corporações mais poderosas do capitalismo globalizado. Do mesmo modo, permite compreender a produção de cenários de injustiça ambiental conceituada e assente como "o mecanismo pelo qual sociedades desiguais, do ponto de vista econômico e social, destinam a maior carga dos danos ambientais do desenvolvimento às populações de baixa ren$\mathrm{da}$, aos grupos sociais discriminados, aos povos étnicos tradicionais....”.

No campo da Saúde Coletiva, a incorporação dos conceitos da ecologia política amplia o foco do olhar em direção a um melhor entendimento sobre a relação saúde ambiente e aos determinantes socioambientais da saúde, ao incluir os processos sociais e econômicos de desenvolvimento $^{6}$. Dessa forma, a saúde coletiva pode con- gregar em suas análises uma interpretação contextualizada considerando que processos de desenvolvimento, nos quais imperam desigualdades econômicas e sociais, escondem diversos problemas de saúde de países ou regiões, afetando territórios e grupos populacionais específicos, determinando ou condicionando as formas como as pessoas adoecem e morrem.

O texto analisa as questões envolvendo a produção de alumínio e sua importância econômica no atual contexto das economias mundial e brasileira. Na primeira parte será analisada a conjuntura contemporânea da produção de alumínio no mundo, seus aspectos econômicos; a inserção do Brasil neste mercado, assim como os grupos empresariais que atuam em solo nacional. Em seguida, serão abordados os impactos ambientais relacionados à cadeia produtiva do alumínio e os aspectos relacionados à saúde e segurança do trabalhador. Por fim, à luz dos paradigmas supracitados, se propõe uma discussão do modelo de desenvolvimento pautado pela produção e exportação de commodities como o alumínio e seus impactos sobre o ambiente e a saúde coletiva.

\section{Aspectos econômicos da produção de Alumínio Primário}

As particularidades intrínsecas à cadeia produtiva do alumínio têm feito desta atividade, a nível mundial, se deslocar para nações menos desenvolvidas e periféricas como o Brasil. Sem aludir a problemas ambientais relacionados à lavra da bauxita, discutido mais adiante, cabe mencionar que a indústria do alumínio se distingue pelo seu caráter eletro-intensivo. Desta forma, produtores históricos como os Estados Unidos, Japão e Canadá, têm perdido espaço na produção mundial para países como China, Austrália e Rússia e, com os investimentos recentes que têm incrementado a capacidade produtiva, o Brasil ${ }^{7}$.

Do total de alumínio primário produzido no Brasil, 1.534,9 mil ton. em 2009, 1.008,3 mil ton. foram consumidos pelo mercado doméstico. Deve-se acrescentar aos números da produção 275,3 mil ton. de sucata recuperada em território nacional, principalmente através da reciclagem de latas, e 102,4 mil ton. resultantes de importação, o que conferiu um suprimento de 1.912,6 mil ton. de alumínio em $2009^{8}$. Em relação ao mercado externo, o Brasil tem se consolidado, nesta primeira década do século XXI, como um importante exportador de alumínio primário. A 
importância das exportações desse metal pode ser melhor compreendida pela sua participação na composição dos superávits obtidos pelo Brasil no mercado externo: em 2009, apesar da crise internacional, as trocas envolvendo o alumínio ficaram positivas para o Brasil em U\$2.560 milhões, $10 \%$ de todo o saldo comercial calculado em U\$ 25.536 milhões. O Gráfico 1 apresenta os resultados da balança comercial da indústria do alumínio no Brasil entre os anos de 2000 a 2009.

O valor do alumínio na composição dos superávits comerciais do Brasil são sinalizadores de uma transformação estrutural na indústria do alumínio. Se até o final dos anos de 1980 o Brasil era um grande exportador de bauxita, essa condição foi alterada e, atualmente, o alumínio primário assumiu a condição de principal commodity até pouco tempo reservada apenas ao mineral. Foi importante para essa transformação, além da escassez de recursos minerais nos países centrais, a emigração de indústrias altamente poluidoras e impactantes ao meio ambiente para nações periféricas, como o Brasil. Nestas nações ${ }^{10}$, a pressão social pela qualidade ambiental é menor, sendo que na maioria das vezes a instalação de empreendimentos impactantes ao meio ambiente é enxergada de forma positiva por representar crescimento econômico e geração de empregos.

\section{Grupos empresariais atuantes no Brasil}

Apesar do volume elevado de produção, tanto de bauxita quanto de alumina e alumínio primário, são poucos os grupos que operam no Brasil. Estes são formados por empresas e capitais nacionais e internacionais, sendo que algumas vezes se encontram associados. A seguir serão descritos os principais grupos.

A Mineração Rio do Norte $(\mathrm{MRN})^{11}$ está localizada no complexo de Porto Trombetas, no município de Oriximiná no estado do Pará. A MRN, criada em 1974, é uma associação de empresas nacionais e internacionais, cujo objetivo era o de produzir bauxita. A MRN, atualmente, é uma das maiores instalações de produção de bauxita do mundo, com capacidade estimada em 18,1 milhões de toneladas por ano. Em 1972, a então Cia. Vale do Rio Doce (CRVD) e a canadense Alcan planejaram reiniciar o projeto criando uma joint-venture. Finalmente, em 1974 foi assinado o acordo de acionistas criando a Mineração Rio do Norte S.A., atualmente composto pelas empresas: Vale (40\%), a australiana BHP Billiton Metais (14,8\%), a anglo-canadense Rio Tinto Alcan (12\%), a Companhia Brasileira de Alumínio (CBA) $(10 \%)$, a norte-americana Alcoa Brasil (8,58\%), a norueguesa Norsk Hydro $(5 \%)$, a Alcoa World Alumina (5\%) e a norteamericana Abalco $(4,62 \%)^{12}$.

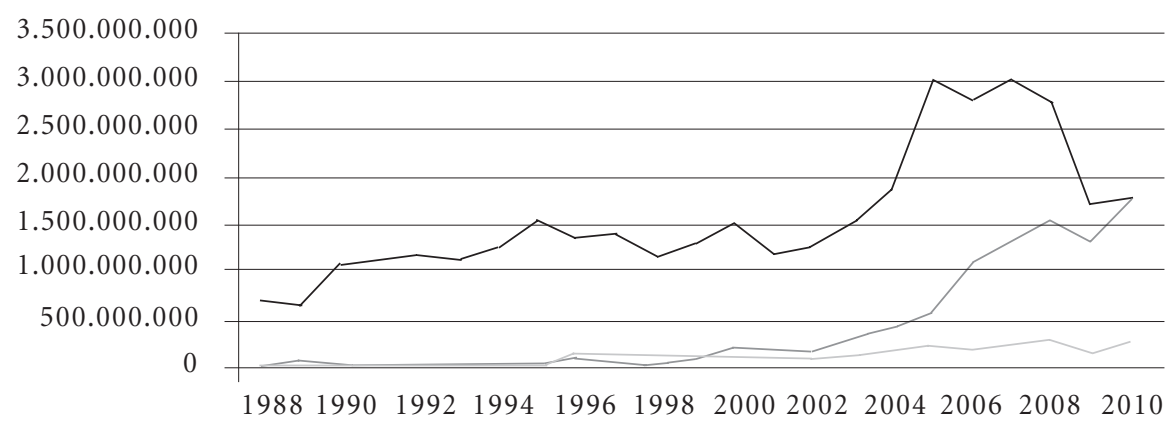

$$
\begin{aligned}
& \text { Bauxita } \\
& \text { Alumina } \\
& \text { Alumínio }
\end{aligned}
$$

Gráfico 1. Saldo comercial da indústria do alumínio entre 2000 a 2009 em dólares. 
A Vale ${ }^{13}$, empresa brasileira privatizada em 1997, atua em todas as etapas de produção da cadeia do alumínio, desde a extração da bauxita, passando pelo refino da alumina e a produção do alumínio. Após a fase de coleta de informações para a confecção do presente artigo, o setor de alumínio da Vale foi negociado para a empresa norueguesa Norsk Hydro. Desta forma esta empresa assumiu todos os ativos correspondentes à extração de bauxita e a produção de alumínio no Brasil, até então geridos pela Vale. Além da participação acionaria na Mineração Rio do Norte S.A. (MRN) (40\%), a empresa tem participação majoritária na Alumina do Norte do Brasil S.A. (Alunorte) (57\%), localizada em Barcarena no estado do Pará, e na Alumínio Brasileiro S.A. (Albras), também situada nesta cidade (51\%). O fornecimento de bauxita para a planta de Barcarena é realizado pela Vale em uma unidade produtiva em Paragominas, também no estado do Pará. A produção de bauxita em Paragominas está integrada a unidade de Barcarena por um mineroduto de 244 quilômetros. Já na produção de alumínio primário a Vale tem participação na Albras, subsidiária da Alunorte, com capacidade produtiva de 455 mil toneladas de alumínio primário por ano.

A Albras, está instalada no município de Barcarena, no estado do Pará. A empresa foi constituída em 1978 e instalada em 1985, fruto de uma associação da brasileira Vale e da Nippon Amazon Aluminium Co. Ltda. (NAAC), um consórcio de 17 empresas japonesas com participação majoritária do Japan Bank for international Cooperation, organismo do governo japonês ${ }^{14}$.

A Alunorte foi criada em 1978 a partir de um acordo entre os governos do Brasil, na época com a participação da Cia. Vale do Rio Doce, e do Japão para a produção conjunta de alumina. Localizada no município de Barcarena, no estado do Pará, a unidade iniciou a produção no ano de 1995 e ostenta atualmente a condição de maior produtora de alumina do planeta. A alumina processada é dividida de acordo com a participação acionária de cada empresa. Os principais acionistas da Alunorte são: as nacionais Vale $(57,3 \%)$ e CBA $(3,62 \%)$, a norueguesa Norsk Hydro $(34,03 \%)$, as japonesas NAAC $(2,59 \%)$, Mitsui $(2,19 \%)$ e Japan Alunorte Investiments (JAIC) $(0,54 \%)^{15}$.

A Novelis ${ }^{16}$ deu início a suas atividades no Brasil em 2005, a partir da cisão dos ativos da Alcan, herdando os empreendimentos desta empresa nos ramos da extração de bauxita e produção de alumina e alumínio primário. A em- presa possui duas unidades produtoras no Brasil, estabelecidas nos municípios de Aratu, na Bahia, e Ouro Preto, Minas Gerais. A partir de 2007, a Novelis foi incorporada pela Hindalco Industries Limited, empresa do grupo indiano Aditya Birla e maior produtora de alumínio integrado e de cobre da Ásia.

A $\mathrm{CBA}^{17}$, ligada ao Grupo Votorantim, teve sua unidade produção inaugurada em 1955, localizada na cidade paulista de Alumínio em São Paulo. A planta desta empresa é a maior do planeta com operação totalmente verticalizada, concentrando todas as etapas da produção, do processamento da bauxita à produção de alumínio em um mesmo local. A empresa detém também $10 \%$ de participação na MRN e uma nova unidade de extração de bauxita no município de Miraí em Minas Gerais.

O Consórcio de Alumínio do Maranhão (Alumar $)^{18}$, inaugurado em 1984, é formado pelas empresas Alcoa, Rio Tinto Alcan e BHP Billiton. A planta, localizada no município de São Luís no Maranhão, é uma das maiores do mundo na produção de alumínio primário e alumina.

A Alcoa ${ }^{19}$ está presente no Brasil há 45 anos. A empresa possui unidades produtivas em Poços de Caldas, Minas Gerais, São Luís no Maranhão (Alumar) e Juruti, no estado do Pará. A participação acionária de $8,5 \%$ na MRN permite a empresa a produzir alumina e alumínio primário na unidade de São Luís (Alumar), sendo que a bauxita explorada em Juruti vem atender a demanda desta unidade, o que contribuiu para sua expansão; Já a unidade de Poços de Caldas, onde também é produzido alumina e alumínio, é abastecida de bauxita minerada neste mesmo município.

\section{Questões Socioambientais}

A cadeia produtiva do alumínio produz sérios impactos ambientais, os quais são difusos e produzidos em todas as etapas do processo. A seguir, são descritos esses impactos.

\section{Extração da bauxita}

Para a exploração da bauxita é retirada a vegetação superficial com o uso de tratores. Em seguida a camada de solo fértil é removida e estocada em separado para ser usada durante o processo de recuperação. Vale mencionar que em várias ocasiões após a recuperação, a economia que se segue se pauta no plantio de eucaliptos, uma atividade monocultora e também impactante ao meio ambiente. Cada tonelada de bauxita beneficiada produz em média 1,5 toneladas 
de escória. Considerando-se a produção brasileira de 2005, estimada em 21,19 milhões de ton. de bauxita, chega-se a um número de 31,78 milhões de ton. de escória, na forma de uma lama vermelha formada principalmente por óxidos de alumínio, ferro, silício e titânio. Todo esse material é depositado em imensas barragens que funcionam como reservatórios, representando um passível ambiental e riscos ${ }^{20}$. Na Amazônia brasileira, a bauxita é extraída em áreas de floresta preservada, onde existe uma forte dependência entre os habitantes locais e o ambiente. Para alguns autores, nessa região, a mineração tem deixado para traz um rastro de impactos ambientais, de pobreza e de subdesenvolvimento ${ }^{21}$.

$\mathrm{Na}$ Zona Mata de Minas Gerais, a bauxita é minerada nas partes mais elevadas, em regiões de serras. O desflorestamento é realizado em frações da Mata Atlântica em áreas de recarga hidrológi$\mathrm{ca}$, deixando o solo exposto às intempéries. A topografia inclinada, associada às condições climáticas da região, contribui para a lixiviação de materiais particulados em direção às vargens e aos cursos de água. Há que se considerar ainda a perca da biodiversidade pela retirada dos animais de seu habitat com a devastação dos ecossistemas. A recuperação das áreas degradadas pela atividade é realizada após a bauxita ser exaurida.

\section{Energia}

A indústria do alumínio é eletro-intensiva Em 2009 para a produção de uma tonelada do metal foram consumidos em média 15,4 Mwh de energia elétrica. Desta forma, os grandes produtores mundiais de alumínio, necessariamente, são importantes consumidores e, por vezes, produtores de energia elétrica. Este fato contribui para a existência de uma relação entre os países grandes detentores de parques hidrelétricos e os principais produtores de alumínio primário. No ano de 2004, com exceção da Austrália, os oito maiores produtores de alumínio (China, Rússia, Canadá, Estados Unidos, Brasil, Austrália, Noruega e Suécia), tinham na hidroeletricidade uma das mais importantes fontes de energia ${ }^{22}$.

No ano de 2009, segundo a Associação Brasileira do Alumínio ${ }^{8}$, foram consumidos 23.880,6 Gwh no processo de produção de alumínio pelas empresas nacionais e 1.998,3 Gwh para a redução de alumina, perfazendo um total de 25.878,9 Gwh. O perfil de voracidade das indústrias de alumínio no consumo de energia pode ser mais bem abalizado ao relacioná-lo à energia produzida pelo Sistema Interligado Nacional (SIN) ${ }^{23}$. Da energia elétrica gerada no Brasil durante o ano de 2009, 445.662,85 Gwh, algo em torno de $5,8 \%$ desse total foi consumido pelas indústrias produtoras de alumínio. Este volume corresponde a quase a metade de toda a energia elétrica produzida na região Nordeste $(47,6 \%)$ e a $62,50 \%$ da energia gerada na região Norte do país.

De acordo com a Associação Brasileira de Alumínio $(\mathrm{ABAL})^{8}$, a indústria nacional de alumínio tem investido em usinas privadas, alcançando 31\% de energia elétrica própria. Atualmente, estão sendo construídas as seguintes unidades de usinas privadas para gerarão de energia elétrica: UHE (Usina Hidrelétrica) Estreito com 1.087 Mwh e UHE Serra do Facão com 210 Mwh, perfazendo um total de $1.297 \mathrm{Mwh}$; sendo que estão em operação as unidades de UHE Candonga, UHE Ourinhos, UHE Piraju, UHE Machadinho, UHE Barra Grande e UHE Campos Novos, com um total de produção de $2.984 \mathrm{Mwh}$ de energia. No ano de 2006, havia em processo de licenciamento ambiental usinas de geração com capacidade produtiva de $2.705 \mathrm{Mwh}^{24}$.

Contrariando o paradigma propalado pela ABAL e pelas empresas produtoras de alumínio que defendem as hidrelétricas como sendo uma matriz de energia limpa, estas têm produzido elevados impactos socioambientais no Brasil e no mundo ${ }^{25}$. O caráter de insustentabilidade ambiental das grandes hidrelétricas pode ser avaliado a partir de parâmetros que identificam os problemas físico-químicos-biológicos originários da implantação, da operação e de sua interação com as características dos locais de sua instalação. Bermann ${ }^{26}$ destaca que entre os principais problemas ambientais gerados pelas hidrelétricas estão:

- a alteração do regime hidrológico dos rios;

- o comprometimento da qualidade das águas devido ao caráter lêntico das represas que prejudicam a decomposição de rejeitos e efluentes;

- o assoreamento dos reservatórios consequentes das ocupações que retiram a vegetação e a mata ciliar;

- a emissão de gases do efeito estufa (metano) decorrentes da decomposição da cobertura vegetal submersa;

- a proliferação de vetores transmissores de doenças endêmicas;

- a monopolização do uso da água, cuja prioridade é a geração de energia em detrimento de outros usos como irrigação, pesca lazer etc., além de poder deixar submersa cidades e patrimônios culturais.

Sevá Filho ${ }^{27}$ lembra o fato de que as hidrelétricas ainda funcionam como "engrenagens for- 
midáveis de acumulação de capital e de mobilização de forças de trabalho". Para o autor, existe uma ideologia dominante que impõe ao país a opção barrageira como sendo a única existente ou viável, dissimulando os verdadeiros interesses ou razões para os projetos hidrelétricos, como no caso de Tucuruí, que foi construída "para fundir alumínio e beneficiar minérios, com os consumidores brasileiros bancando os rombos de contratos lesivos da Eletronorte com as indústrias consumidoras de energia”.

Cabe mencionar, ainda, que os empreendimentos hidrelétricos são marcados por impactos ambientais que muitas vezes se transformam em conflitos onde se posicionam, estando de um lado grandes grupos empresariais ou o próprio Estado e, do outro, grupos sociais e populações atingidas, que se organizam para resistirem ao que pode ser considerada uma situação de injustiça ambiental. Uma análise no sítio da Rede Brasileira de Justiça Ambiental ${ }^{28}$ manifesta a existência de 194 documentos de todo o Brasil, relacionados a conflitos envolvendo a construção de barragens hidrelétricas. Os conflitos são difusos e envolvem majoritariamente grupos sociais vulneráveis. Em um desses empreendimentos, a CBA, ao construir uma hidrelétrica no Vale do Ribeira (SP), UHE Tijuco Alto, que tem por escopo a geração de energia para a ampliação de sua planta de produção de alumínio na cidade do mesmo nome, é acusada de desconsiderar a cultura regional, não levando em conta o histórico do uso da terra pelas comunidades que há anos habitam as áreas que serão inundadas ${ }^{29}$. Os conflitos envolvendo a construção de hidrelétricas e comunidades e pequenos produtores rurais são recorrentes também em Minas Gerais, com seu importante potencial hidroelétrico ${ }^{30-36}$, assim como em outras regiões do Brasil ${ }^{37,38}$.

\section{Insumos, Emissões e Efeito Estufa}

A redução da bauxita em alumina e, posteriormente, a transformação desta em alumínio, consome um volume considerável de insumos. Somente para a produção de alumina, no ano de 2009, foram consumidos 950,7 mil ton. de óleo combustível; 816,8 mil ton. de soda cáustica; e 128,7 mil ton. de cal. Para a produção de alumínio, em 2009, além de 23.713,8 GWh de energia elétrica e de 2.880,6 mil ton. de alumina, foram necessários 532,5 mil ton. de coque; 166,2 mil ton. de piche; 32,8 mil ton. de fluoreto; e 2,4 mil ton. de criolita, todos insumos que contêm inúmeras substâncias tóxicas ${ }^{8}$.
A dimensão das poluições atmosféricas originárias das indústrias produtoras de alumínio pode ser melhor dimensionada ao analisarmos alguns relatórios produzidos pelas secretarias e órgãos estaduais de meio ambiente. Em Minas Gerais foi elaborado, com base nos indicadores de 2005, um inventário relativo às emissões de gases de efeito estufa, segundo as atividades socioeconômicas. No setor de processos industriais, a indústria do alumínio participou com 13\% do total de emissão de gases, ficando atrás, apenas, das indústrias de cimento $(43,9 \%)$ e cal $(38,2 \%)^{39}$. Já no inventário de emissões de fontes fixas de $\mathrm{CO}^{2}$, elaborado pela $\mathrm{CETESB}^{40}$, em 2008, as indústrias de minerais não metálicos (nesta tipologia estavam incluídos além da produção de alumínio primário, fornos de cal, cimento e produção de vidro) no estado de São Paulo, ocupavam a segunda posição como emissores de $\mathrm{CO}^{2}$, contribuindo com 26,4\% do total estadual. Já no ranking das empresas que mais emitiram $\mathrm{CO}^{2}$ em 2008, a CBA se apresentou na sexta colocação. Outros inventários de outros estados da federação também apontam o potencial emissor de $\mathrm{CO}^{2}$ das indústrias de alumínio primário: na Bahia, em inventário produzido pela Secretaria de Meio Ambiente ${ }^{41}$, referente ao ano de 2008, a indústria de alumínio primário emitiu 6,5\% do total de $\mathrm{CO}^{2}$, se posicionando na sexta colocação. No estado do Rio de Janeiro, a indústria do alumínio, ranqueou-se na quinta colocação em volume de emissões totais de gases do efeito estufa em 2005 e em primeiro lugar, entre as indústrias, em emissões de metano e óxido nitroso ${ }^{42}$. Nos Estados Unidos, dois fatos relacionados às emissões de gases tóxicos pelas indústrias de alumínio chamam a atenção: um diz respeito à subnotificação das emissões por parte das empresas que são captados pelos inventários da EPA; outro sugere a diminuição das emissões devido ao deslocamento das empresas para o exterior ${ }^{43}$.

\section{Segurança e saúde do trabalhador}

Conforme sugerem Milanez e Porto ${ }^{4}$, "as condições de segurança e saúde do trabalhador são importantes indicadores de gestão ambiental, entretanto, pouco são divulgadas pelas empresas”. Os trabalhadores das empresas são diretamente impactados pelos processos produtivos sendo os primeiros a sofrerem com as emissões e acidentes ${ }^{4}$.

De acordo com a $\mathrm{ABAL}^{8}$, os padrões brasileiros de proteção e gerenciamento dos riscos são idênticos aos utilizados no mundo todo e o nú- 
mero total de acidentes registrados em 2009 foi de 453, apresentando uma baixa de 106 ocorrências em relação a 2008, tendência contrária à que vem ocorrendo nas outras atividades produtivas no Brasil.

Já a análise dos totais de acidentes, considerando-se a Classificação Nacional de Atividades Econômicas (CNAE) ${ }^{44}$, refuta os números apontados pela $\mathrm{ABAL}^{8}$. Os números de acidentes classificados pela $\mathrm{CNAE}^{44}$ são aqueles ocorridos durante os processos de extração mineral da bauxita e na produção de alumínio, não sendo levados em consideração os chamados acidentes de trajeto. As informações do Ministério da Previdência Social (MPS) ${ }^{45}$ apontam para um incremento nas ocorrências de acidentes totais da cadeia produtiva do alumínio, sobremaneira, no processo industrial (Gráfico 2).

Os números baixos de acidentes, relacionados à extração de bauxita, podem estar associados à mecanização da produção e à baixa participação humana na extração. Por sua vez, os acidentes inventariados durante o processo de produção do alumínio, iniciada em 2006, apontam para uma tendência de alta acentuada (nesse ano houve um incremento nas notificações de mais de $720 \%$, em relação a 2005). As diferenças entre as informações carecem de uma discussão mais acurada. Todavia, se pode especular que as desconexões entre os números podem estar associados a uma subnotificação por parte das informações disponibilizadas pela ABAL e/ou pelo acréscimo do número de acidentes, condicionados pelo incremento da produção, que podem, por sua vez, estar associado a uma precarização das condições de trabalho nos últimos anos, em particular com os trabalhadores terceirizados que mais sofrem com a precarização $0^{46}$.

\section{Discussão}

A análise das informações e dos dados apresentados demonstra que a produção brasileira de alumínio tem sido ascendente, o que, por sua vez, tem adicionado pressão sobre outros setores, como o de geração de energia elétrica, dado o caráter eletrointensivo dessa indústria. Conforme já mencionado, a geração de energia hidrelétrica esbarra em importantes questões socioambientais que são desconsideradas na construção de grandes empreendimentos com o objetivo de

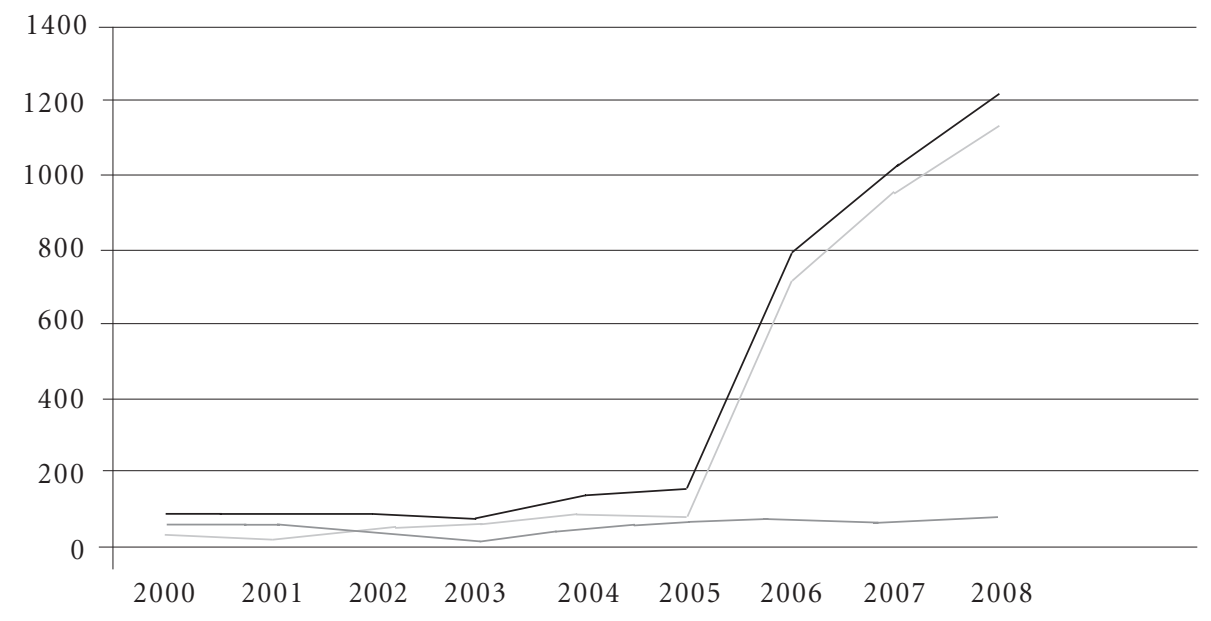

Extração bauxita

Produção de alumínio

Total

Gráfico 2. Acidentes de trabalho em números absolutos. 
garantir energia a baixo custo para a produção e, em boa parte, à exportação de alumínio a um preço competitivo. Desta forma, "em nome de uma concepção industrialista de progresso, desestruturam-se as condições materiais de existência de grupos socioculturais territorialmente referenciados" 1 . O paradigma de desenvolvimento, típico desses projetos, baliza-se pela noção de crescimento econômico distinta da de desenvolvimento proposta por Sachs ${ }^{47}$, que deveria significar "a expiação e reparação das desigualdades passadas", a qual deveria ter por objetivo maior, "promover a igualdade e maximizar a vantagem daqueles que vivem em piores condições". O conceito de desenvolvimento atual, cunhado sob a égide globalização econômica, é, de acordo com Porto e Pacheco ${ }^{48}$, produto de "critérios produtivistas e consumistas que desrespeitam a vida humana e os ecossistemas, bem como a cultura e os valores dos povos nos territórios onde os investimentos e as cadeias produtivas se realizam". Em oposição a esse modelo de desenvolvimento, Harvey $^{49}$ postula que há o de acumulação por espoliação, cujas características são a expulsão de populações camponesas e tradicionais, o aumento de um proletariado sem terra e a privatização de recursos antes partilhados (muitas vezes sob os auspícios do Banco Mundial), em detrimento das formas autóctones e alternativas de produção, ambientalmente mais sustentáveis e socialmente mais justas.

Os impactos socioambientais da cadeia produtiva do alumínio vão além dos problemas relacionados às barragens. A extração da bauxita é realizada após a retirada da vegetação original, muitas vezes em áreas de nascentes. Além da lixiviação de material particulado para o leito de mananciais, é constante o risco de rompimento das barragens onde são depositados os rejeitos do beneficiamento da bauxita, como no episódio ocorrido no município de Barcarena, no estado do Pará, quando foi derramado no rio Murucupi efluentes originários desse processo ${ }^{50}$; ou quando da ocasião do rompimento em uma barragem localizada no município de Miraí, em Minas Gerais, em que milhões de litros de rejeitos foram despejados em um afluente do rio $\mathrm{Pa}$ raíba $\mathrm{Sul}^{51}$; ou, ainda, em um dos maiores acidentes ambientais ocorridos na Europa, quando rompeu uma barragem de uma indústria de alumínio na Hungria, em que foi derramada uma imensa quantidade de lama tóxica, fato que causou não apenas prejuízos financeiros, mas também danos à saúde da população das regiões atingidas $^{52}$. Nesses cenários, populações muitas ve- zes distantes são atingidas pelos empreendimentos minerais, numa forma de partilha desigual das externalidades que atingem grupos mais vulnerabilizados, como aqueles que dependem dos rios para a sobrevivência.

Mesmo em relação às emissões atmosféricas, apesar da ABAL e das empresas produtoras sinalizarem que têm trabalhado para reduzir as emissões de gases do efeito estufa, as informações dos inventários estaduais apontam que as indústrias de alumínio primário têm se posicionado na dianteira daquelas que mais os geram no Brasil. Com o aumento da produção e das exportações, a indústria de alumínio primário vem contribuindo substancialmente para os problemas ecológicos globais responsáveis pelas mudanças climáticas. Há que ressaltar o fato de que, entre os elementos presentes nas emissões, se encontram os CFC (clorofluorcarbono), que ao deteriorar a camada de ozônio, potencializam o risco de efeitos nocivos à saúde, como a incidência de câncer de pele, queimaduras solares e alterações genéticas em humanos, vegetais e animais ${ }^{53}$.

A produção de resíduos, assim como as crescentes emissões relacionadas à cadeia produtiva do alumínio, apresenta-se como um desafio tanto para a manutenção da biodiversidade quanto da saúde coletiva de populações que estão, direta ou indiretamente, envolvidas no processo produtivo. Desta feita, torna-se necessária a adoção de modelos alternativos de desenvolvimento que, por sua vez, possam se articular de forma tenaz às necessidades e características dos territórios e das populações que os ocupam.

Do mesmo modo, merece ser pontuada a controvérsia no que diz respeito às informações fornecidas pelas indústrias em seus sítios na web. Assim como o observado por Milanez e Porto ${ }^{4}$ em relação às empresas siderúrgicas que atuam no Brasil, as indústrias de alumínio primário, de um modo geral, não divulgam de forma detalhada determinadas informações, como as relativas a acidentes de trabalho, emissões de poluentes e séries históricas. Também não existe uma homogeneização nas informações fornecidas, sendo estas escolhidas, ao que parece de forma criteriosa, sobre as atividades que apresentam bom desempenho. Outras informações, quando divulgadas, são feitas com extrema economia de detalhes. Informa-se, por exemplo, sobre as políticas de segurança no trabalho, mas são omitidos os relatos e as estatísticas sobre os acidentes; ou então, quando se divulga a intenção de redução das emissões, não se esclarece seu volume atual e nem as metas a serem alcançadas. 
A transformação do Brasil em importante exportador de alumínio primário também pode ser melhor compreendida como sendo o resultado daquilo que Harvey ${ }^{49}$ chama de revolução tecnológica produtiva, onde o cerne da dominação social reside nos processos estruturais de um novo modelo de acumulação, batizado por este autor de pilhagem. Para esse autor, a lógica atual do capitalismo não faz uso apenas de seus mecanismos tradicionais de acumulação, mas também "mediante práticas predatórias, a fraude e a extração violenta, que se aplicam aproveitando as desigualdades e assimetrias interregionais, para pilhar diretamente os recursos de países mais frágeis" ${ }^{24}$, como é o caso do Brasil e, especialmente, das regiões mais pobres onde se instalam as companhias mineradoras. Muito embora haja uma compensação financeira por parte das empresas como forma de mitigação, estas nunca são suficientes para cobrir os prejuízos provocados pela externalização, pois, conforme sugerido por Altvater ${ }^{55}$, "se fosse exigida a compensação plena dos danos, a transferência jamais seria efetivada".

O modelo exportador brasileiro de commodities, alimentado por produtos como o alumínio, esconde a subvalorização do meio ambiente, da biodiversidade, da mão-de-obra e da saúde das populações mais vulneráveis, o que explica a deterioração do intercâmbio desigual especificada nos preços. Concordando com as ideias de Martinez-Alier ${ }^{56}$, a noção de intercâmbio comercial desigual deve ser redimensionada para que sejam consideradas as externalidades ambientais locais não contabilizadas. Desta forma, Martinez-Alier ${ }^{56}$ conceitua como "intercâmbio ecologicamente desigual" e "dumping ecológico" a exportação de produtos originários de países ou de regiões pobres, como a América Latina, África e Ásia, desconsiderando as externalidades negativas envolvidas em seus processos de produção e o esgotamento dos recursos naturais. O cenário do atual do comércio internacional é gerador de circuitos de energia, materiais e distribuição de riquezas sintetizadas em um metabolismo social que tem contribuído para intensificar as desigualdades sociais e a degradação ambiental ${ }^{6}$. Assim, "quando um país rico importa matérias-primas baratas no mercado de commodities, também está importando recursos naturais como água e o solo, de outras regiões em territórios afastados onde ocorre a degradação ambiental e social" ${ }^{57}$.

Dessa forma, se torna importante compreender que o modelo de desenvolvimento, pauta- do pelo incremento da exportação de commodities, se articula diretamente ao processo de produção de saúde e doença das populações envolvidas. Os impactos ambientais produzidos nos territórios se refletem diretamente nas questões relacionadas à qualidade de vida das populações, tais como a perda de territórios e a diminuição de áreas produtivas (no caso da mineração).

Fato também preocupante é o sinalizado pelo aumento dos acidentes de trabalho que redimensionam os riscos de danos à saúde dos trabalhadores envolvidos no processo produtivo do alumínio. A verificação dos dados disponíveis no sítio do Ministério do Trabalho ${ }^{58}$, assim como os divulgados pela $\mathrm{ABAL}^{8}$, indica certa estabilidade no número de acidentes na etapa produtiva da bauxita, o que por sua vez pode ser resultado da elevada mecanização do processo. Todavia, os números podem estar escondendo os acidentes de trabalho das muitas empresas terceirizadas, como as ligadas ao transporte, que orbitam como empresas parceiras no processo produtivo. No processo produtivo do alumínio, ao se considerar os dados levantados, percebe-se que o incremento da produção na última década, tem sido acompanhado pela sombra constante dos acidentes de trabalho. A precarização das condições de trabalho, articulada ao aumento da produção de alumínio, pode ser a chave para a compreensão de um mosaico onde o resultado tem sido o crescente número de acidentes e danos à saúde dos trabalhadores.

Por fim, conforme sublinhado por Franco ${ }^{59}$, o modelo econômico atual, traduzido pelo processo de globalização, tem feito ressurgir com maior força a exclusão social e a cisão socioeconômica entre os países do Norte e do Sul, ricos e pobres e a cristalização dos problemas ambientais locais e globais. $\mathrm{O}$ fato de países emergentes como o Brasil e os do chamado BRIC apresentarem taxas de crescimento econômico elevada, ainda que permita uma maior presença econômica e política no cenário internacional e a implementação de políticas sociais que possam reduzir taxas de pobreza absoluta, se fragiliza diante de um modelo que continua a se basear, em boa medida, na exploração degradante de recursos naturais e seres humanos, na externalização dos impactos sociais, ambientais e sanitários, assim como na produção de commodities que, ainda que parcialmente de origem industrial, caracterizam-se pelo relativo baixo valor agregado. 


\section{Considerações finais}

Procuramos apresentar neste artigo um breve panorama do atual estágio da cadeia produtiva do alumínio no Brasil. Pode-se perceber que a produção de alumínio primário vem crescendo nos últimos anos, na mesma intensidade que as exportações. Com isso, da condição de exportador de bauxita, o Brasil transformou-se em um importante exportador mundial de alumínio. Todavia, essa melhora aparente, marcada pela aparente agregação de valor, deixa a montante um rastro onde as marcas são os acidentes de trabalho, os difusos danos ambientais, produzidos desde a extração da bauxita à produção final do alumínio, tributários à determinação de cenários danosos para a saúde coletiva. Ainda, o caráter eletro-intensivo da produção escamoteia a ocorrência de conflitos envolvendo, muitas vezes, pequenos produtores, quilombolas e povos da floresta, que tem seus territórios alagados para a geração de energia elétrica.

A partir das informações discutidas ao longo do texto, percebe-se que o Brasil tem aumentado sua participação no mercado internacional atendendo exatamente aos interesses das nações mais ricas que se beneficiam da importação de commodities, cuja produção e exportação de mercadorias como o alumínio, vão ao encontro das necessidades estratégicas dessas nações em não produzi-lo em condições socioambientais desfavoráveis. Desta forma, nações periféricas ou emergentes, como o Brasil, inevitavelmente terão como efeitos colaterais a produção de cenários caracterizados por tragédias socioambientais locais e globais, justificados por um modelo que visa aumentar e sustentar suas taxas de crescimento do PIB sem considerar as externalidades negativas produzidas.

\section{Colaboradores}

AB Henriques e MFS Porto participaram igualmente de todas as etapas de elaboração do artigo. 


\section{Referências}

1. Acselrad H, Mello CCA, Bezerra GN. O que é justiça ambiental? Rio de Janeiro: Garamond; 2009.

2. Schütz GE, Tambellini, AT, Asmus, CIRF, Meyer A, Câmara VM. A agenda da sustentabilidade global e sua pauta oficial: uma análise crítica na perspectiva da Saúde Coletiva. Cien Saude Colet 2012; 17(6):14071418.

3. Buss PM, Machado JMH, Gallo E, Magalhães DP, Setti AFF, Franco Netto FA, Buss DF. Governança em saúde e ambiente para o desenvolvimento sustentável. Cien Saude Colet 2012; 17(6):1479-1491.

4. Milanez B, Porto MFS. Gestão Ambiental e Siderurgia: limites e desafios no contexto da globalização. RGSA 2009; 3(1):4-21.

5. Bullard RD. Enfrentando o racismo ambiental no século XXI. In: Acselrad H, Herculano S, Pádua JA, organizadores. Justiça ambiental e cidadania. Rio de Janeiro: Editora Relume-Dumará; 2004. p. 41-66.

6. Porto MFS, Martinez-Alier J. Ecologia política, economia ecológica e saúde coletiva: interfaces para a sustentabilidade do desenvolvimento e para a promoção da saúde. Cad Saude Publica 2008; 23(Supl. 4):S503-S512.

7. Departamento Nacional de produção Mineral (DNPM). Sumário Mineral 2009. Brasília: DNPM; 2009.

8. Associação Brasileira do Alumínio (ABAL). Anuário Estatístico 2009. São Paulo: ABAL; 2010.

9. Sistema Integrado de Comércio Exterior (SISCOMEX). Balança comercial da indústria do alumínio entre 2000 a 2009. [documento na Internet]. [acessado 2010 fev 10]. Disponível em: http://www. aliceweb.desenvolvimento.gov.br

10. Freitas APG, Monte-Mor RLM, Braga, TM. Desenvolvimento, Meio Ambiente e Divisão Internacional do Trabalho: Análise empírica para uma região de concentração de indústrias sujas e intensivas em recursos naturais no estado de Minas Gerais. Belo Horizonte: UFMG, Cedeplar; 2003.

11. Mineração Rio do Norte (MRN). Mineração Rio do Norte - História. [documento na Internet]. [acessado 2010 nov 5]. Disponível em: http://www.mrn. com.br/pt-BR/Paginas/default.aspx

12. Instituto Observatório Social. Estudo da cadeia produtiva do Alumínio na Região Norte do Brasil: o caso da empresa MRN. São Paulo: Instituto Observatório Social; 2008.

13. Vale. Sobre a Vale. [documento na Internet]. [acessado 2010 nov 30]. Disponível em: http://www. vale.com/brasil/PT/aboutvale/Paginas/default.aspx

14. Alumínio Brasileiro S.A. (Albras). Apresentação. [documento na Internet]. [acessado 2010 nov 30]. Disponível em: http://www.albras.net/apresentacao. htm

15. Instituto Observatório Social. Estudo da cadeia produtiva do Alumínio na Região Norte do Brasil: o caso da empresa ALUNORTE. São Paulo: Instituto Observatório Social, 2008.

16. Novelis. Sobre a Novelis. [documento na Internet]. [acessado 2010 nov 30]. Disponível em: http://www. novelis.com/pt-br/Paginas/About-Novelis.aspx
17. Votorantim Metais. Instucional. [documento na Internet]. [acessado 2010 nov 30]. Disponível em: http://www.vmetais.com.br/pt BR/Institucional/ Paginas/QuemSomos.aspx

18. Consórcio de Alumínio do Maranhão (Alumar). Alumar. [documento na Internet]. [acessado 2010 nov 30]. Disponível em: http://www.alumar.com.br/ internas_template 4 .aspx?tbsid $=2$

19. Alcoa Alumínio S.A. (Alcoa). Alcoa no Brasil. [documento na Internet]. [acessado 2010 nov 30]. Disponível em: http://www.alcoa.com/brasil/pt/info_ page/unidades.asp

20. Souza Costa ET, Guilherme LRG, Curi N, Oliveira LCA, Visioli EL, Lopes G. Subproduto da indústria do alumínio como amenizante de Solos contaminados com cádmio e chumbo. Rev. Bras. Ciên. Solo 2008; 32(6):2533-2546.

21. Bunker S. Underdeveloping the Amazon. Chicago: University of Chicago Press; 1985.

22. Souza AN, Jacobi PR. A Indústria do Alumínio no Brasil e suas Hidrelétricas sob a Perspectiva da Modernização Ecológica. In: IX ENGEMA Encontro Nacional sobre Gestão Empresarial e Meio Ambiente; 2007; Curitiba.

23. Operador Nacional do Sistema Elétrico (ONS). Geração de energia. [documento na Internet]. [acessado 2010 nov 30]. Disponível em: http://www. ons.org.br/historico/geracao_energia.aspx

24. Midea LG. Análise Econômica Financeira Comparativa da Autoprodução Direta ou Conectada no SIN Um Estudo de Caso [dissertação]. São Paulo: Escola Politécnica da Universidade de São Paulo; 2009.

25. Dupas G. O Impasse Ambiental e a Lógica do Capital. In: Dupas G, organizador. Meio ambiente e crescimento econômico, tensões estruturais. São Paulo: Editora da Unesp; 2008.

26. Bermann C. Impasses e Controvérsias da Hidroeletricidade. Revista Estudos Avançados 2007; 21(59):139153.

27. Sevá Filho AO. Estranhas Catedrais. Notas sobre o capital hidrelétrico, a natureza e a sociedade. Ciênc. cult. (São Paulo) 2008; 60(3):44-50

28. Rede Brasileira de Justiça Ambiental. Banco Temático. [documento na Internet]. [acessado 2010 nov 30]. Disponível em: http://www.justicaambiental. org.br/_justicaambiental/busca_acervo.php

29. Moruzzi MPE, Ferrarini OG. Perspectivas em concorrência: crítica e justificação diante dos projetos de construção de barragens no Ribeira de Iguape/ SP. In: Anais do IV Encontro Nacional da ANPPAS; 2008; Brasília.

30. Zhouri A, Zucarelli MC. Visões da Resistência: conflitos ambientais no Vale do Jequitinhonha. In: Souza JVA, Henriques MS, organizadores. Vale do Jequitinhonha: formação histórica, populações e movimentos. Belo Horizonte: UFMG, PROEX; 2010. p. $109-236$.

31. Zhouri A, Zucarelli MC. Mapa dos conflitos ambientais no Estado de Minas Gerais - notas preliminares de uma pesquisa em andamento. In: Anais do IV Encontro Nacional da ANPPAS. 04 a 06 de junho de 2008; Brasília, DF. 
32. Zhouri A, Oliveira R. Desenvolvimento, Conflitos Sociais e Violência no Brasil Rural: O caso das usinas hidrelétricas. Rev. Ambiente \& Sociedade 2007; 10(2):119-135.

33. Zhouri A, Gomes LA. Da Invisibilidade à Mobilização Popular: atores e estratégias no licenciamento ambiental das hidrelétricas Capim Branco I e II. In: Anais do II Seminário Nacional Movimentos Sociais, Participação e Democracia; 2007; Florianópolis.

34. Zhouri A, Pinheiro MFB. Conflitos sociais e institucionais na concretização recente de algumas concessões de aproveitamentos hidrelétricos assinadas entre 1997 e 2000. In: Anais do XI Congresso Brasileiro de Energia; 2006; Rio de Janeiro.

35. Penido M. A Hidrelétrica de Candonga/MG e a Produção Capitalista do Espaço: conflitos, resistências e re-existências do lugar. In: Anais do IV Encontro Nacional da ANPPAS; 2008; Brasília.

36. Pinto VFS, Pereira DB. Conflitos socioambientais e resistências no/do projeto hidrelétrico de Candonga. Geografias 2005; 1(1):70-85.

37. Alves JM. Hidrelétrica de Belo Monte: a apresentação de um projeto e as representações sociais que circulam em torno do conceito de desenvolvimento. In: IV Encontro da ANPPAS; 2010; Florianópolis.

38. Junk WJ, Nunes de Mello JAS. Impactos ecológicos das represas hidrelétricas na bacia amazônica brasileira. Rev Estudos Avançados 1990; 4(8):126-143.

39. Minas Gerais. Fundação Estadual do Meio Ambiente. Inventário de emissões de gases do efeito estufa do estado de Minas Gerais, ano base 2005. Belo Horizonte: Fundação Estadual do Meio Ambiente; 2006.

40. São Paulo. Companhia de Tecnologia de Saneamento Ambiental do estado de São Paulo (CETESB). Relatório do inventário estadual de fontes fixas de emissões de $\mathrm{CO}^{2}$ - fontes industriais - combustíveis fósseis. São Paulo: CETESB; 2008.

41. Bahia. Secretaria Estadual de Meio Ambiente. Primeiro Inventário de emissões antrópicas de gases de efeito estufa do Estado da Bahia. Salvador: Secretaria Estadual de Meio Ambiente; 2010.

42. Rio de Janeiro. Secretaria de Estado de Meio Ambiente. Inventário de emissões de gases do efeito estufa do estado do Rio de Janeiro. Rio de Janeiro: Secretaria de Estado de Meio Ambiente; 2007.

43. Koehler DA, Spengler JD. The toxic realese inventory: fact or fiction? A case study of the primary aluminum industry. J Environ Manage 2007; 85(2): 296-307.

44. Classificação Nacional de Atividades Econômicas (CNAE). Concla - Comissão Nacional de Classificação. [documento na Internet]. [acessado em 2011 jan 28]. Disponível em: http://www.cnae.ibge. gov.br/

45. Brasil. Ministério da Previdência Social. Estatísticas da Previdência Social. [documento na Internet]. [acessado 2010 nov 5]. Disponível em: http:// www.previdencia.gov.br/conteudoDinamico. php?id $=423$
46. Minayo Gomez C, Thedim-Costa SMF. Precarização do trabalho e desproteção social: desafios para a saúde coletiva. Cien Saude Colet 1999; 4(2):411421.

47. Sachs I. Desenvolvimento includente, sustentável, sustentado. Rio de Janeiro; Garamond: 2008.

48. Porto MFS, Pacheco T. Conflitos e injustiça ambiental em saúde no Brasil. Tempus. Actas em Saúde Coletiva 2009; 4(4):31.

49. Harvey D. O novo imperialismo. São Paulo: Contexto; 2005.

50. Instituto Evandro Chagas, Seção de Meio Ambiente. Caracterização preliminar dos impactos ambientais, danos ao ecossistema e riscos à saúde decorrentes do lançamento no rio Murucupi de efluentes do processo de beneficiamento de bauxita, Barcarena, Pará (relatório). Belém; Instituto Evandro Chagas: 2009.

51. Brasil. Ministério de Minas e Energia. Departamento Nacional de Produção Mineral (DNPM). Gestão Mineral. Boletim Informativo do Departamento Nacional de Produção Mineral 2007; 3(22).

52. Enserink M. After Red Mud Flood, Scientists Try to Halt Wave of Fear and Rumors. Science 2010; 330(6003):432-433.

53. Freitas CM, Porto MFS. Saúde, Ambiente e sustentabilidade. Rio de Janeiro: Editora Fiocruz; 2006.

54. Breilh J. Pilhagens, ecossistemas e saúde. In: Miranda AC, Barcellos C, Moreira JC, Monken M, organizadores. Território, Ambiente e Saúde. Rio de Janeiro: Editora Fiocruz; 2008. p. 159-180.

55. Altvater E. O preço da riqueza. São Paulo: Editora da Unesp; 1995.

56. Martinez-Alier J. O ecologismo dos pobres. São Paulo: Contexto; 2007.

57. Porto MFS. Uma ecologia política dos riscos: princípios para integrarmos o local e o global na promoção da saúde e da justiça ambiental. Rio de Janeiro: Editora da Fiocruz; 2007.

58. Brasil. Ministério do Trabalho (MT). Estatísticas. [documento na internet]. [acessado 2010 nov 8]. Disponível em: http://portal.mte.gov.br/geral/estatisticas. htm

59. Franco T. Padrões de produção e consumo nas sociedades urbano-industriais e suas relações com a degradação da saúde e do meio ambiente. In: Minayo MC, Miranda AC, organizadores. Saúde e ambiente sustentável: estreitando nós. Rio de Janeiro: Editora da Fiocruz; 2010.

Artigo apresentado em 11/05/2012

Aprovado em 23/06/2012

Versão final apresentada em 13/07/2012 